\title{
Epigallocatechin-3-gallate prevents oxidative stress-induced cellular senescence in human mesenchymal stem cells via Nrf2
}

\author{
JOO-HYUN SHIN ${ }^{1 *}$, HYO-JIN JEON ${ }^{1 *}$, JIHYE PARK $^{1}$ and MI-SOOK CHANG ${ }^{1,2}$ \\ ${ }^{1}$ Laboratory of Stem Cell and Neurobiology, Department of Oral Anatomy, School of Dentistry and Dental Research Institute, \\ ${ }^{2}$ Neuroscience Research Institute, Seoul National University, Seoul 03080, Republic of Korea
}

Received June 1, 2016; Accepted July 26, 2016

DOI: $10.3892 / \mathrm{ijmm} .2016 .2694$

\begin{abstract}
Human mesenchymal stem cells (hMSCs) have great therapeutic potential due to their high plasticity, immune privileged status and ease of preparation, as well as a lack of ethical barriers to their use. However, their ultimate usefulness is limited by cellular senescence occurring secondary to increased cellular levels of reactive oxygen species (ROS) during their propagation in culture. The underlying molecular mechanisms responsible for this process in hMSCs remain unclear. An antioxidant polyphenol epigallocatechin-3-gallate (EGCG) found in green tea, is known to activate nuclear factor-erythroid 2-related factor 2 (Nrf2), a master transcriptional regulator of antioxidant genes. Herein, we examined the EGCG-mediated antioxidant mechanism in hMSCs exposed to ROS which involves Nrf2 activation. The $\mathrm{H}_{2} \mathrm{O}_{2}$-exposed hMSCs showed cellular senescence with significantly increased protein levels of acetyl-p53 and p21 in comparison with the untreated hMSCs, and these effects were prevented by pre-treatment with EGCG. By contrast, in Nrf2-knockdown hMSCs, EGCG lost its antioxidant effect, exhibiting high levels of acetyl-p53 and p21 following EGCG pre-treatment and $\mathrm{H}_{2} \mathrm{O}_{2}$ exposure. This indicates that Nrf2 and p53/p21 may be involved in the anti-senescent effect of EGCG in hMSCs. Taken together, these findings indicate the important role of EGCG in preventing oxidative stress-induced cellular senescence in hMSCs through Nrf2 activation, which has applications for the massive production of more suitable hMSCs for cell-based therapy.
\end{abstract}

\section{Introduction}

Bone marrow-derived human mesenchymal stem cells (hMSCs) are a desirable cell source for cell-based therapy

Correspondence to: Professor Mi-Sook Chang, Laboratory of Stem Cell and Neurobiology, Department of Oral Anatomy, School of Dentistry and Dental Research Institute, Seoul National University, 101 Daehak-ro, Jongno-gu, Seoul 03080, Republic of Korea

E-mail: mschang@snu.ac.kr

${ }^{*}$ Contributed equally

Key words: cellular senescence, mesenchymal stem cell, oxidative stress, polyphenol, reactive oxygen species owing to their high plasticity, immune privileged status and ease of preparation, as well as a lack of ethical barriers to their use. They also have high self-renewal capacity with sustained proliferation in vitro $(1,2)$. However, obtaining the large numbers of cells required for therapeutic applications is often problematic as hMSCs are subject to the Hayflick limit, a finite proliferation capacity in vitro and replicative senescence after long-term culture (3-5). Senescent cells have shown reduced multipotency, clonogenicity and subsequent arrest of proliferation, thus limiting the regenerative potential of hMSCs necessary for the desired therapeutic effects (5).

Cellular senescence is characterized by irreversible cell cycle arrest, despite continued metabolic activity and viability. Senescence is caused by inadequate culture conditions, such as culture shock or cellular stress $(3,4)$. The stress-induced premature senescence (SIPS) of human stem cells may be induced by subcytotoxic stress $\left(\mathrm{H}_{2} \mathrm{O}_{2}\right.$, histone deacetylase inhibitors and radiation) $(5,6)$.

Oxidative stress, mediated by reactive oxygen species (ROS) including hydrogen peroxide $\left(\mathrm{H}_{2} \mathrm{O}_{2}\right)$, superoxide anion radical, hydroxyl radical and peroxide, plays a crucial role in the induction of SIPS $(3,4)$. Sublethal concentrations of $\mathrm{H}_{2} \mathrm{O}_{2}$ may damage cellular components including DNA, which leads to low metabolic activity and cell cycle arrest through the activation of either the p53/p21 or the p16/pRb pathway (7). Notably, p53 acetylation, which is induced by Sirt1, the human homolog of yeast SIR2, has been proposed to promote senescence (8-11). Acetylation of p53 is a translational modification that results in the activation of p53. Cellular senescence was observed in serially-passaged and $\mathrm{H}_{2} \mathrm{O}_{2}$-treated human dermal fibroblast cells and acetyl-p53 levels were markedly increased compared with phosphorylated p53 levels (12). These findings suggest an association between oxidative stress-mediated senescence and p53 acetylation.

Polyphenols, or polyphenolic compounds, are widely distributed in nature. Polyphenols, such as the green tea polyphenol epigallocatechin-3-gallate (EGCG), have been demonstrated to exhibit various biological properties, including DNA damage protection and free radical scavenging (13). Furthermore, polyphenols are pharmacologically safe compounds in humans (14). In addition to the ability to act as a neutralizing agent of excessive ROS, EGCG exerts antioxidant, anti-inflammatory and anti-tumorigenic effects (15). Recently, EGCG has been shown to suppress $\mathrm{H}_{2} \mathrm{O}_{2}$-mediated apoptotic cell death in hMSCs (16). It is well 
known that EGCG exerts an antioxidant effect by activating the nuclear factor-erythroid 2-related factor 2 (Nrf2) signaling pathway, which is involved in the cellular antioxidant defense system (17). Nrf2 activation is closely regulated by Kelch-like ECH-associated protein 1 (Keap1), a substrate adaptor for Cul3-based E3 ligase, which targets Nrf2 for proteasomal degradation (18). In response to oxidative stress, Nrf2 upregulates the expression of antioxidant and detoxifying genes by binding to antioxidant response elements (AREs) in the promoter region of the encoding genes $(19,20)$.

The purpose of this study was to examine the novel molecular mechanisms underlying the anti-senescent effect of EGCG in $\mathrm{H}_{2} \mathrm{O}_{2}$-exposed hMSCs. Our data demonstrated that EGCG reversed $\mathrm{H}_{2} \mathrm{O}_{2}$-induced oxidative stress by downregulating the p53-p21 signaling pathway and upregulating Nrf2 expression. Nrf2-knockdown hMSCs showed significantly increased protein levels of acetyl-p53 and p21 following EGCG pre-treatment and $\mathrm{H}_{2} \mathrm{O}_{2}$ exposure, which suggests a potential role for $\mathrm{Nrf} 2$ in $\mathrm{p} 53 / \mathrm{p} 21$ regulation to thereby prevent oxidative stress-induced cellular senescence in hMSCs.

\section{Materials and methods}

Culture of hMSCs. Adult bone marrow-derived hMSCs were purchased from Cambrex (Walkersville, MD, USA). hMSCs (passages 4-10) were cultured in Dulbecco's modified Eagle's medium (DMEM) low glucose containing 10\% fetal bovine serum (FBS) (both from Gibco, Grand Island, NY, USA) at $37^{\circ} \mathrm{C}$ with $5 \% \mathrm{CO}_{2}$.

EGCG treatment and exposure of cells to $\mathrm{H}_{2} \mathrm{O}_{2}$. EGCG and $\mathrm{H}_{2} \mathrm{O}_{2}$ were purchased from Sigma-Aldrich (St. Louis, MO, USA). To define the optimal concentrations for use in subsequent experiments, hMSCs were pre-incubated with different amounts of EGCG (50 and $100 \mu \mathrm{M}$ ) for $6 \mathrm{~h}$ and then the cells were exposed to $200 \mu \mathrm{M} \mathrm{H}_{2} \mathrm{O}_{2}$ (diluted in DMEM supplemented with $10 \%$ FBS) for $2 \mathrm{~h}$. The cells were washed twice with DMEM to remove excess $\mathrm{H}_{2} \mathrm{O}_{2}$ and re-incubated in fresh complete medium for $24 \mathrm{~h}$ to prevent cell death and allow for the observation of senescent characteristics

Cellular senescence assay. The activity of senescence-associated $\beta$-galactosidase (SA $\beta$-gal), a marker of senescence, was analyzed in hMSCs using a cellular senescence assay kit (EMD Millipore, Billerica, MA, USA) according to the manufacturer's instructions. Briefly, the medium was aspirated and the cells were washed once with phosphate-buffered saline (PBS; pH 6.0). After fixing the cells with $1 \mathrm{X}$ fixing solution at room temperature for $10 \mathrm{~min}$, the cells were washed again with PBS and incubated without light for at least $4 \mathrm{~h}$ with prepared $\mathrm{SA} \beta$-gal detection solution at $37^{\circ} \mathrm{C}$ without $\mathrm{CO}_{2}$. The percentage of senescence-stained cells was obtained by counting the number of blue-stained cells and the total number of cells per field under the microscope (CKX41; Olympus, Tokyo, Japan; 100-200 cells in four random fields).

Cell viability assay. Cell viability was analyzed using the 3-(4,5-dimethylthiazol-2-yl)-2,5-diphenyltetrazolium bromide (MTT) method. Briefly, hMSCs were cultured in 24-well tissue culture plates and exposed to $200 \mu \mathrm{M} \mathrm{H}_{2} \mathrm{O}_{2}$ for
$2 \mathrm{~h}$. After $24 \mathrm{~h}$, the cells were stained with $1 \mathrm{mg} / \mathrm{ml} \mathrm{MTT}$ (Sigma-Aldrich). The media were then carefully aspirated and $150 \mu 1$ dimethyl sulfoxide (DMSO) was added to solubilize the colored formazan product. The optical density was read at $554 \mathrm{~nm}$ using a microplate reader (Floustar Optima; BMG Labtech, Ortenberg, Germany).

Western blot analysis. The cells were washed twice with cold PBS and lysed with RIPA buffer [50 mM Tris-HCl, pH 7.4, $150 \mathrm{mM} \mathrm{NaCl}, 1 \% \mathrm{NP}-40,0.25 \%$ sodium deoxycholate, $0.2 \mathrm{mg} / \mathrm{ml}$ leupeptin, $0.2 \mathrm{mg} / \mathrm{ml}$ aprotinin, $0.1 \mathrm{M}$ phenylmethylsulfonylfluoride (PMSF), $1 \mathrm{mM} \mathrm{Na}_{3} \mathrm{VO}_{4}$ and $\left.0.5 \mathrm{M} \mathrm{NaF}\right]$. The lysates were centrifuged at $13,500 \mathrm{x}$ g for $15 \mathrm{~min}$ at $4^{\circ} \mathrm{C}$ and the supernatants were loaded on to $12 \%$ sodium dodecyl sulfate-polyacrylamide gel electrophoresis (SDS-PAGE) gels. The following primary antibodies were used: rabbit anti-p53 (1:1,000; sc-6243; Santa Cruz Biotechnology, Inc., Santa Cruz, CA, USA); rabbit anti-acetyl p53 (1:1,000; 06-758; Upstate Biotechnology, Lake Placid, NY, USA); mouse anti-p21 (1:2,000; sc-6246) and rabbit anti-Nrf2 (1:1,000; SC-722) (both from Santa Cruz Biotechnology, Inc.); mouse anti- $\alpha$-tubulin (1:5,000; T5168; Sigma-Aldrich) and goat antilamin B (1:2,000; sc-6216; Santa Cruz Biotechnology, Inc.). Primary antibodies were detected using horseradish peroxidase-conjugated goat anti-mouse (A2554), -rabbit (A0545) (Sigma-Aldrich), or donkey anti-goat secondary antibodies (sc-2020; Santa Cruz Biotechnology, Inc.) and visualized using an enhanced chemiluminescence detection system (Thermo Fisher Scientific, Rockford, IL, USA).

Subcellular fractionation. To obtain nuclear and cytoplasmic fractions, the cells were harvested and suspended in ice-cold cytoplasmic lysis buffer (10 mM HEPES, pH 7.9, $10 \mathrm{mM}$ $\mathrm{KCl}, 1.5 \mathrm{mM} \mathrm{MgCl}_{2}, 0.5 \mathrm{mM}$ DTT and $0.2 \mathrm{mM}$ PMSF) on ice for $15 \mathrm{~min}$. The suspensions were then centrifuged at $13,500 \mathrm{x} \mathrm{g}$ for $10 \mathrm{~min}$ at $4^{\circ} \mathrm{C}$ and the supernatants were saved as the cytoplasmic fractions. The pellets were resuspended in nuclear lysis buffer (20 mM HEPES, pH 7.9, 20\% glycerol, $0.4 \mathrm{M} \mathrm{NaCl}, 1.5 \mathrm{mM} \mathrm{MgCl}_{2}, 0.2 \mathrm{mM}$ EDTA, $0.5 \mathrm{mM}$ DTT and $0.2 \mathrm{mM}$ PMSF) and incubated on ice for $40 \mathrm{~min}$ with occasional gentle shaking. The suspensions were then centrifuged at $13,500 \mathrm{x} \mathrm{g}$ for $15 \mathrm{~min}$ and the supernatants were used as nuclear fractions. Quantification of the results of western blot analysis was performed using ImageJ software (NIH, Bethesda, MD, USA).

Immunocytochemistry. The hMSCs were pre-incubated with $100 \mu \mathrm{M}$ EGCG for $6 \mathrm{~h}$, fixed in PBS containing 4\% PFA and incubated overnight at $4^{\circ} \mathrm{C}$ with rabbit anti-Nrf2 (1:100). Alexa Fluor 546 anti-rabbit IgG (Invitrogen, Carlsbad, CA, USA) was used as a secondary antibody. The cells were counterstained with $100 \mathrm{ng} / \mathrm{ml}$ 4,6-diamidino-2-phenylindole (DAPI) (Santa Cruz Biotechnology, Inc.) for nuclear staining and visualized using a confocal laser scanning microscope (FV300; Olympus).

Transfection of small interfering RNA (siRNA). Human Nrf2-specific siRNA oligonucleotides (SMARTpool) were purchased from Dharmacon (Lafayette, CO, USA). The following target specific siRNA sequences were used: 5'-UAAAGUGGCUGCUCAGAAU-3'; 5'-GAGUUACAGUG 
A

B

C
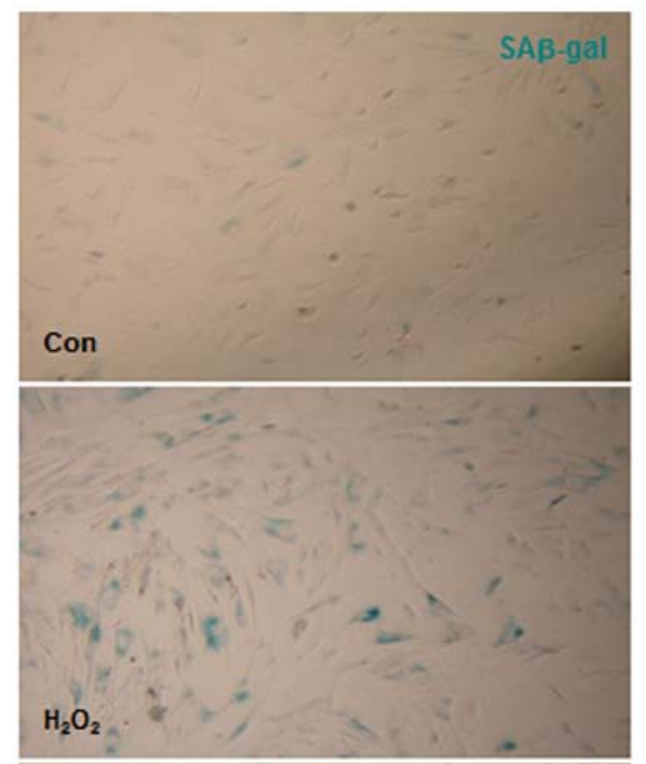

D

\section{$50 \mu \mathrm{MEGCG}+\mathrm{H}_{2} \mathrm{O}_{2}$}

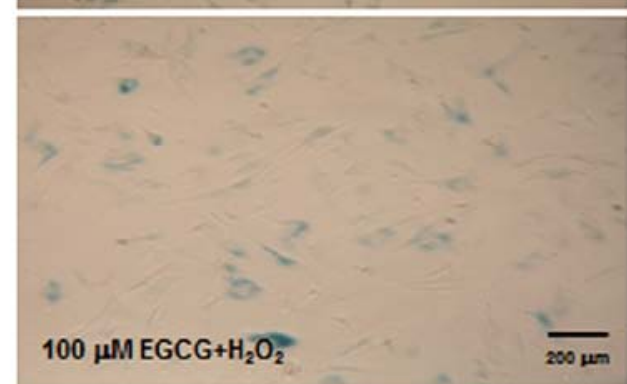

E
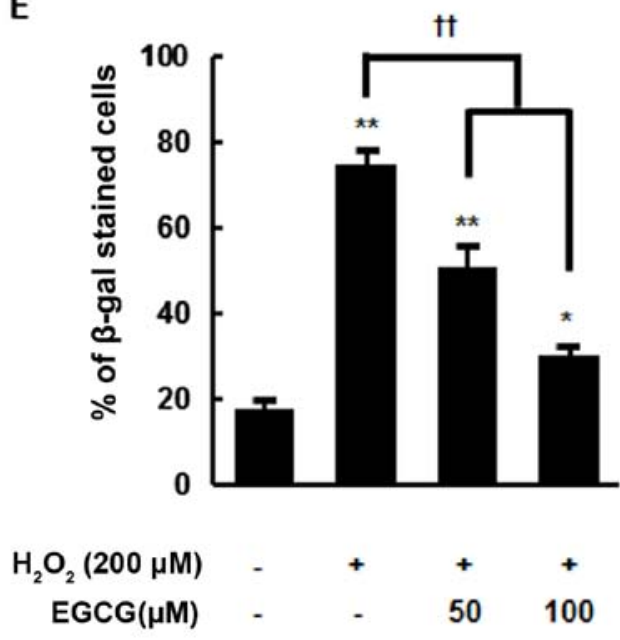

$\mathbf{F}$

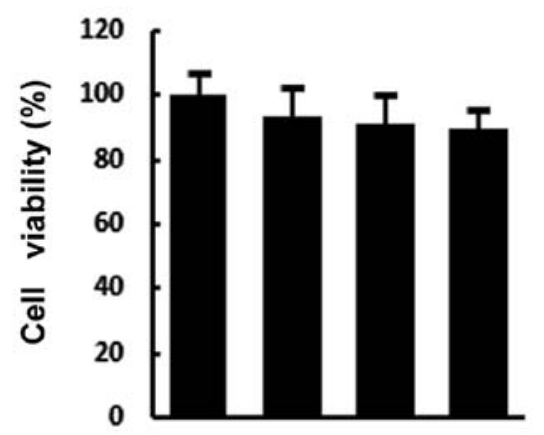

$\begin{array}{rcccc}\mathrm{H}_{2} \mathrm{O}_{2}(200 \mu \mathrm{M}) & - & + & + & + \\ \operatorname{EGCG}(\mu \mathrm{M}) & - & - & 50 & 100\end{array}$

Figure 1. Epigallocatechin-3-gallate (EGCG) pre-treatment reduces cellular senescence in $\mathrm{H}_{2} \mathrm{O}_{2}$-treated human mesenchymal stem cells (hMSCs). (A-D) Senescence-associated $\beta$-galactosidase (SA $\beta$-gal) staining of control (Con) and hMSCs before and after $\mathrm{H}_{2} \mathrm{O}_{2}$ exposure. hMSCs were treated with 50 or $100 \mu \mathrm{M}$ of EGCG for $6 \mathrm{~h}$ and then exposed to $\mathrm{H}_{2} \mathrm{O}_{2}(200 \mu \mathrm{M})$ for $2 \mathrm{~h}$. Twenty-four hours after $\mathrm{H}_{2} \mathrm{O}_{2}$ exposure, the cells were stained with SA $\beta$-gal (blue cytoplasmic stain). Scale bar, $200 \mu \mathrm{m}$. (E) Quantification of SA $\beta$-gal activity. (F) Cell viability of hMSCs. MTT assays were performed $24 \mathrm{~h}$ after $\mathrm{H}_{2} \mathrm{O}_{2}$ exposure. Changes in cell survival observed in three independent experiments are presented as the means \pm SEM. ${ }^{*} \mathrm{P}<0.05$ and ${ }^{* *} \mathrm{P}<0.01 \mathrm{vs}$. the control; ${ }^{*} \mathrm{P}<0.01 \mathrm{vs}$. the $\mathrm{H}_{2} \mathrm{O}_{2}$ groups. ANOVA followed by a post hoc Newman-Keuls test.

UCUUAAUA-3'; 5'-UGGAGUAAGUCGAGAAGUA-3'; and 5'-CACCUUAUAUCUCGAAGUU-3'. Non-targeting scrambled 20-25 nt siRNA oligonucleotides (Santa Cruz Biotechnology, Inc.) were used as a control. Transient transfections were performed using DharmaFECT 3 transfection reagent (Dharmacon) according to the manufacturer's instructions. Briefly, siRNA/lipid complexes were added to the wells at a final concentration of $100 \mathrm{nM}$ siRNA and $1 \mu \mathrm{l} /$ well of DharmaFECT 3. Nrf2 gene expression was determined at $48 \mathrm{~h}$ after transfection.

Statistical analysis. Statistical analysis was performed by analysis of variance (ANOVA) followed by a post hoc Newman-Keuls test. P-values $<0.05$ were considered to indicate a statistically significant difference. All data are presented as the means \pm standard error of mean (SEM).

\section{Results}

EGCG pre-treatment reduces cellular senescence in $\mathrm{H}_{2} \mathrm{O}_{2}$ treated hMSCs. The stimulation of cells with exogenous ROS activates various signaling pathways that result in DNA damage, cellular senescence and apoptosis (3). In order to examine the effects of $\mathrm{H}_{2} \mathrm{O}_{2}$ exposure on cellular senescence, the hMSCs were exposed to $200 \mu \mathrm{M} \mathrm{H}_{2} \mathrm{O}_{2}$ diluted in DMEM supplemented with $10 \%$ FBS for $2 \mathrm{~h}$, in order to allow the observation of senescent characteristics without significant cell death. In the present study, the activity of SA $\beta$-gal was measured by $\mathrm{SA} \beta$-gal staining at $24 \mathrm{~h}$ after $\mathrm{H}_{2} \mathrm{O}_{2}$ exposure. Approximately $75 \%$ of $\mathrm{H}_{2} \mathrm{O}_{2}$-exposed hMSCs were positive for $\mathrm{SA} \beta$-gal (blue cytoplasmic stain) $(74.6 \pm 3.6 \%$ ), whereas only $20 \%$ of the control cells without $\mathrm{H}_{2} \mathrm{O}_{2}$ exposure were SA $\beta$-gal-positive $(\mathrm{P}<0.01)$ (Fig. 1A, B and E). However, the 


\section{A}

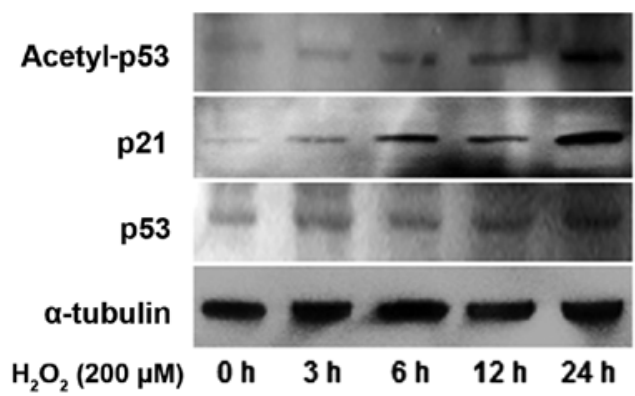

B

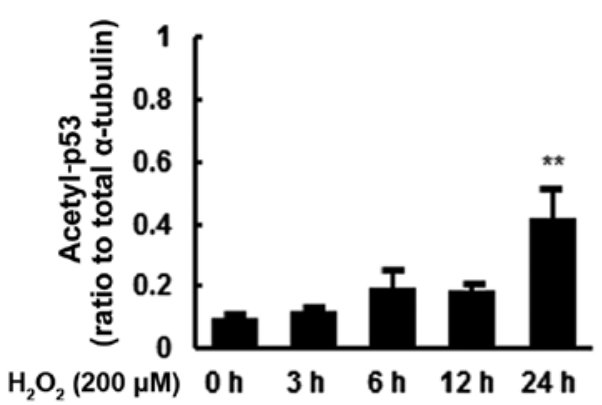

C

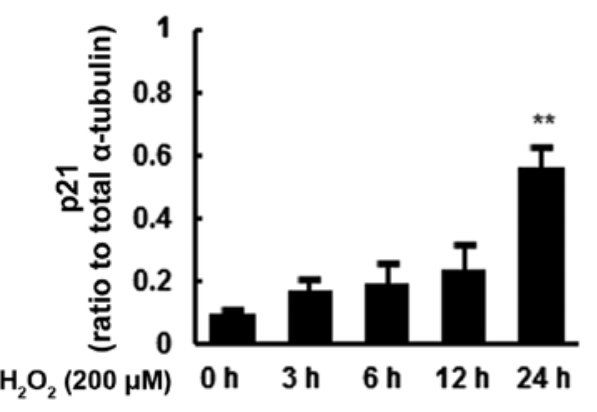

D

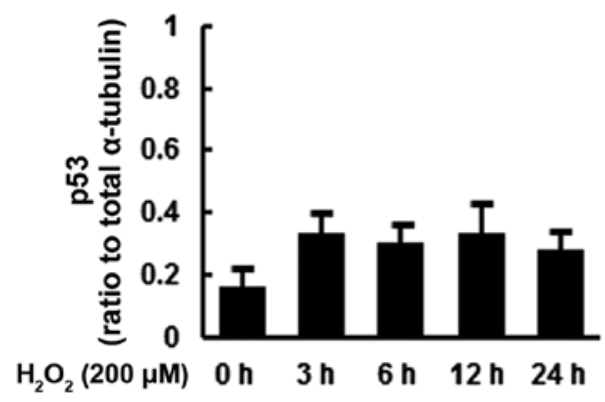

$\mathbf{E}$

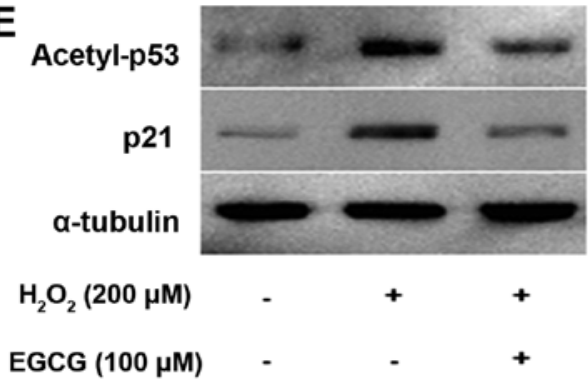

$\mathbf{F}$

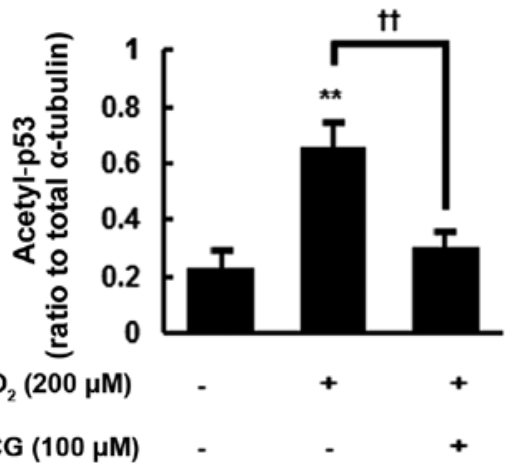

G

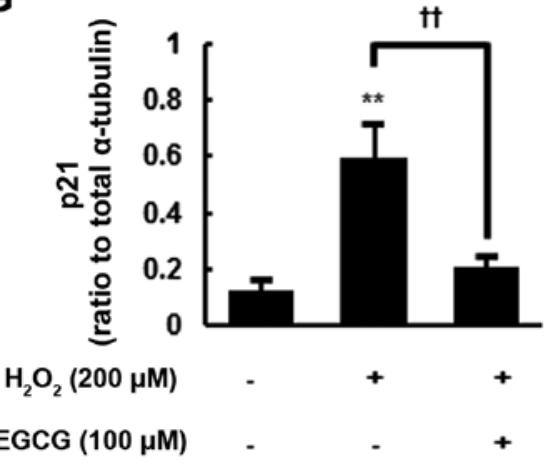

Figure 2. Epigallocatechin-3-gallate (EGCG) pre-treatment reduces $\mathrm{H}_{2} \mathrm{O}_{2}$-induced increases in acetyl-p53 and p21 protein levels in human mesenchymal stem cells (hMSCs). (A-D) Western blot analysis and quantification of acetyl-p53, p21, and p53 protein levels in hMSCs at $0,3,6,12$ or $24 \mathrm{~h} \mathrm{after} \mathrm{H}_{2} \mathrm{O}_{2}(200 \mu \mathrm{M})$ exposure for $2 \mathrm{~h}$. (E-G) Western blot analysis and quantification of acetyl-p53 and p21 protein levels in hMSCs pre-treated with EGCG $(100 \mu \mathrm{M})$ for $6 \mathrm{~h}$ prior to $\mathrm{H}_{2} \mathrm{O}_{2}(200 \mu \mathrm{M})$ exposure for $2 \mathrm{~h}$. The values determined in four independent experiments are presented as the means $\pm \mathrm{SEM} .{ }^{* *} \mathrm{P}<0.01 \mathrm{vs}$. the control; ${ }^{\dagger+} \mathrm{P}<0.01$ vs. $\mathrm{H}_{2} \mathrm{O}_{2}$ group. ANOVA followed by a post hoc Newman-Keuls test.

pre-treatment of hMSCs with 50 or $100 \mu \mathrm{M}$ EGCG for $6 \mathrm{~h}$ reduced the percentage of SA $\beta$-gal-positive cells following $\mathrm{H}_{2} \mathrm{O}_{2}$ exposure to $50.7 \pm 4.8$ and $30.4 \pm 1.9 \%$, respectively $(\mathrm{P}<0.01)$ (Fig. 1C-E). Taken together, these results suggest that cellular senescence in hMSCs is accelerated by $\mathrm{H}_{2} \mathrm{O}_{2}$ exposure and EGCG pre-treatment reduces this acceleration in a dose-dependent manner. Furthermore, there were no significant differences in cell death among the experimental groups, indicating that $\mathrm{H}_{2} \mathrm{O}_{2}$ exposure induced cellular senescence without causing significant cell death (Fig. 1F).
EGCG pre-treatment reduces $\mathrm{H}_{2} \mathrm{O}_{2}$-induced increases in acetylated p53 and p 21 protein levels in hMSCs. To further evaluate $\mathrm{H}_{2} \mathrm{O}_{2}$-induced changes in senescent cells, we next examined the protein levels of acetyl-p53, p53 and p21 in hMSCs at different times following $200 \mu \mathrm{M} \mathrm{H}_{2} \mathrm{O}_{2}$ exposure. The expression of p53 and p21 is known to correlate with senescence in human primary cells and p53 acetylation has been shown to strongly promote cellular senescence $(8,12)$. Consistent with the findings of previous studies, there were senescence-associated increases in the protein levels of acetyl-p53, p21 and p53 following 

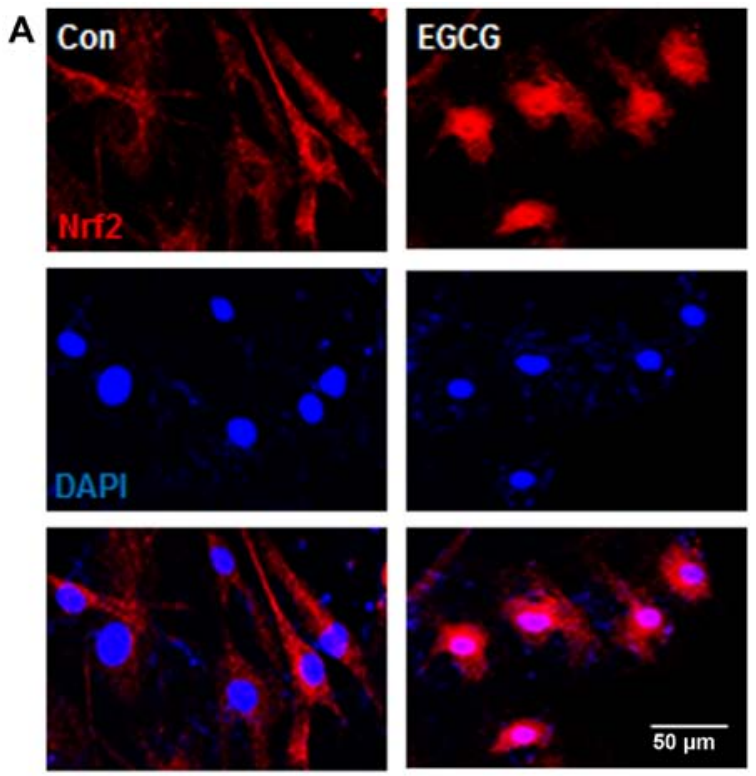

B

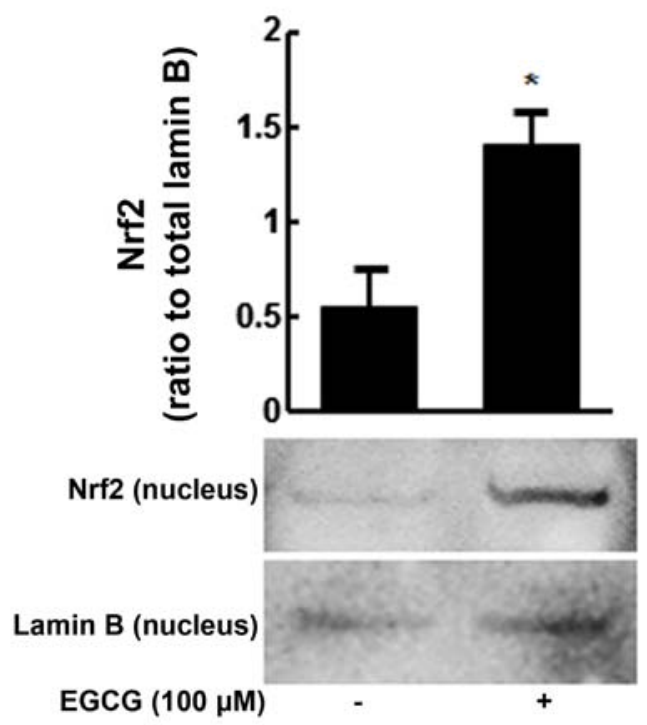

Figure 3. Epigallocatechin-3-gallate (EGCG) pre-treatment induces nuclear factor-erythroid 2-related factor 2 (Nrf2) translocation from the cytoplasm to the nucleus in human mesenchymal stem cells (hMSCs). (A) Immunocytochemical analysis of Nrf2 expression (red; top panels) and nuclear staining with DAPI (blue; middle panels) in hMSCs treated with or without $100 \mu \mathrm{M}$ EGCG for $6 \mathrm{~h}$ (merge image, lower panels). Scale bar, $50 \mu \mathrm{m}$. (B) Western blot analysis and quantification of $\mathrm{Nrf} 2$ expression in the nuclear fraction. The nuclear envelope marker lamin B was used as a positive control of the nuclear fraction. Nrf2 protein levels determined in three independent experiments are presented as the means \pm SEM. ${ }^{*} \mathrm{P}<0.05$ vs. the control.

$200 \mu \mathrm{M} \mathrm{H}_{2} \mathrm{O}_{2}$ exposure (Fig. 2A-D). Particularly after $24 \mathrm{~h}$ of $\mathrm{H}_{2} \mathrm{O}_{2}$ exposure, the protein levels of acetyl-p53 and p21 were significantly increased by up to 4.4- and 5.9-fold, respectively, compared with the controls, $(\mathrm{P}<0.01)$ (Fig. $2 \mathrm{~B}$ and $\mathrm{C})$. Despite an increasing trend in total p53 protein levels following $\mathrm{H}_{2} \mathrm{O}_{2}$ exposure, the increase did not reach statistical significance (Fig. 2D).

Thus, we decided to examine the effect of EGCG pretreatment on acetyl-p53 and p21 protein levels in hMSCs after $24 \mathrm{~h}$ of $\mathrm{H}_{2} \mathrm{O}_{2}$ exposure. As previously shown, there were significant increases in acetyl-p53 and p21 protein levels at $24 \mathrm{~h}$ after $200 \mu \mathrm{M} \mathrm{H}_{2} \mathrm{O}_{2}$ exposure $(\mathrm{P}<0.01)$ (Fig. 2E-G). However, EGCG pre-treatment $(100 \mu \mathrm{M})$ significantly decreased the protein levels of acetyl-p53 and p21 in the $\mathrm{H}_{2} \mathrm{O}_{2}$-exposed hMSCs by $46.3 \pm 8.1$ and $35.1 \pm 6.5 \%(\mathrm{P}<0.01)$, respectively, compared with the cells given no EGCG pretreatment (Fig. 2E-G).

EGCG induces nuclear translocation of Nrf2 in hMSCs. To determine whether the suppression of cellular senescence by EGCG in $\mathrm{H}_{2} \mathrm{O}_{2}$-exposed hMSCs is associated with $\mathrm{Nrf} 2$ activation, we performed double-labeling experiments with anti-Nrf2 antibody and DAPI after $6 \mathrm{~h}$ of EGCG treatment $(100 \mu \mathrm{M})$. Nrf2 was mostly found to be localized in the cytoplasm in the untreated cells (Fig. 3A, left panel). However, marked translocation of Nrf2 to the nuclei was observed after $6 \mathrm{~h}$ of EGCG treatment, although some Nrf2 remained in the cytoplasm (Fig. 3A, right panel). In addition, nuclear fractions were subjected to western blot analysis, showing that pre-treatment with EGCG increased nuclear Nrf2 protein levels 2.5-fold compared with the untreated cells $(\mathrm{P}<0.05)$ (Fig. 3B).

EGCG pre-treatment suppresses $\mathrm{H}_{2} \mathrm{O}_{2}$-induced cellular senescence and the expression of acetyl-p53 and p21 in hMSCs through Nrf 2 activation. We hypothesized that Nrf2 activation may play an important role in the anti-senescence effects of EGCG. To test this hypothesis, we performed SA $\beta$-gal staining at $48 \mathrm{~h}$ after siRNA-mediated Nrf2 knockdown or control siRNA transfection (Fig. 4A). As previously shown in Fig. 1, the percentage of SA $\beta$-gal-positive cells in the $100 \mu \mathrm{M}$ EGCG-pretreated/ $\mathrm{H}_{2} \mathrm{O}_{2}$-exposed group was significantly reduced $(35.1 \pm 2.5 \%)$ compared with the $\mathrm{H}_{2} \mathrm{O}_{2}$-exposed cells without pre-treatment $(78.4 \pm 3.7 \%)(\mathrm{P}<0.01)$ (Fig. 4A, panels $b$ and $\mathrm{c}$ and 4B). However, EGCG-pre-treated and $\mathrm{H}_{2} \mathrm{O}_{2}$-exposed/ Nrf2-siRNA-transfected cells exhibited increased positive staining for $\mathrm{SA} \beta$-gal $(65.6 \pm 3.9 \%)(\mathrm{P}<0.01)$, which is similar to that of the $\mathrm{H}_{2} \mathrm{O}_{2}$-exposed cells (Fig. 4A, panels $\mathrm{b}$ and $\mathrm{d}$ and 4B). By contrast, EGCG-pre-treated $/ \mathrm{H}_{2} \mathrm{O}_{2}$-exposed/ control-siRNA-transfected cells stained positive at a significantly lower rate of $36 \pm 4.2 \%$, which is similar to that of the EGCG-pre-treated/ $\mathrm{H}_{2} \mathrm{O}_{2}$-treated cells (Fig. 4A, panels $\mathrm{c}$ and e and $4 \mathrm{~B})$. We confirmed that $\mathrm{Nrf} 2$ protein levels were reduced to $30 \pm 5.4 \%$ at $48 \mathrm{~h}$ after Nrf2 siRNA transfection compared with the control siRNA $(\mathrm{P}<0.05)$ (Fig. 4C). These results suggest that Nrf2 may play an important role in the anti-senescence activity of EGCG.

We next examined acetyl-p53 and p21 protein levels in Nrf2-knockdown hMSCs. As previously shown (Fig. 2E-G), acetyl-p53 and p21 protein levels were significantly reduced by $44.6 \pm 3.7$ and $39.7 \pm 5.4 \%$, respectively, in the EGCG-pretreated/ $\mathrm{H}_{2} \mathrm{O}_{2}$-exposed cells compared with the $\mathrm{H}_{2} \mathrm{O}_{2}$-exposed cells $(\mathrm{P}<0.01)$ (Fig. 4D-F). However, at $48 \mathrm{~h}$ after Nrf2-siRNA transfection, acetyl-p53 and p21 protein levels were significantly increased in the EGCG-pre-treated $/ \mathrm{H}_{2} \mathrm{O}_{2}$-exposed cells. The protein levels of acetyl-p53 and p21 were similar to those in the $\mathrm{H}_{2} \mathrm{O}_{2}$-exposed cells (Fig. 4D-F). By contrast, control siRNA transfection did not change the acetyl-p53 and p21 protein levels in the EGCG-pre-treated/ $\mathrm{H}_{2} \mathrm{O}_{2}$-exposed cells. Taken together, these results indicate that Nrf2 activation by EGCG 
A
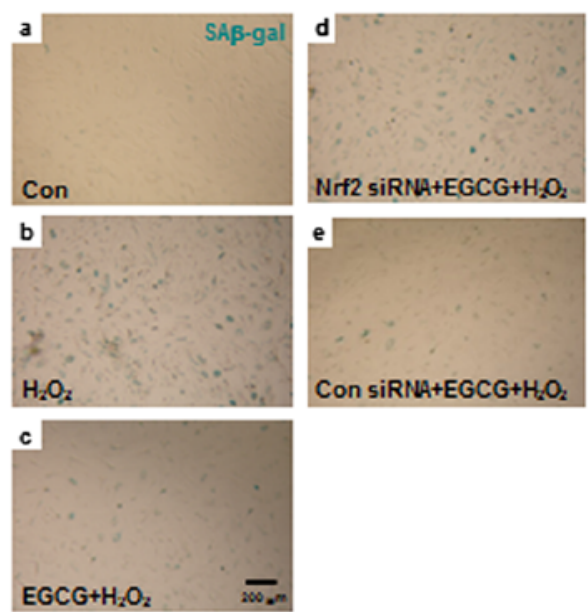

B
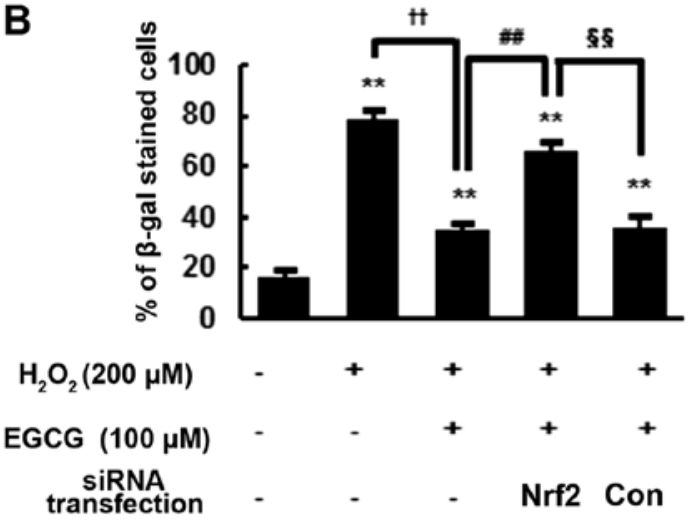

C

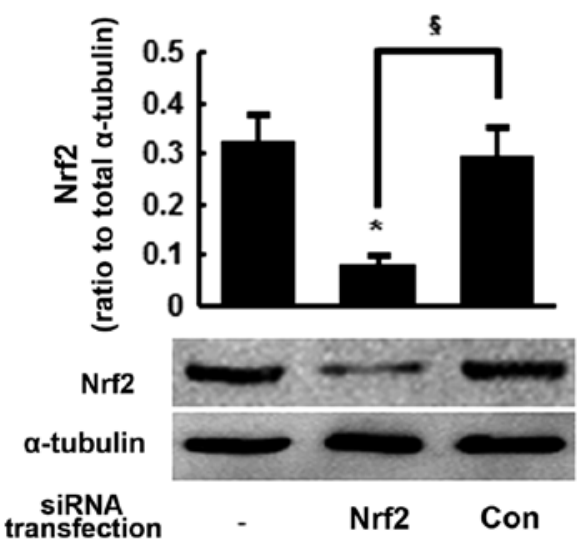

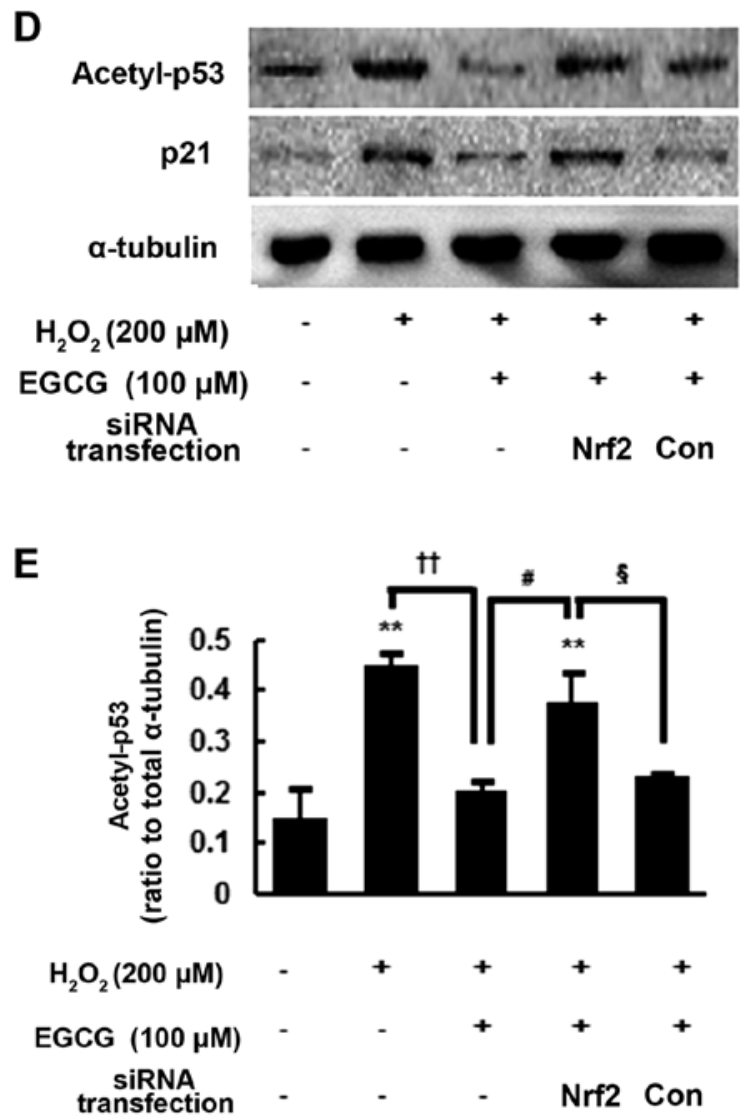

$\mathbf{F}$
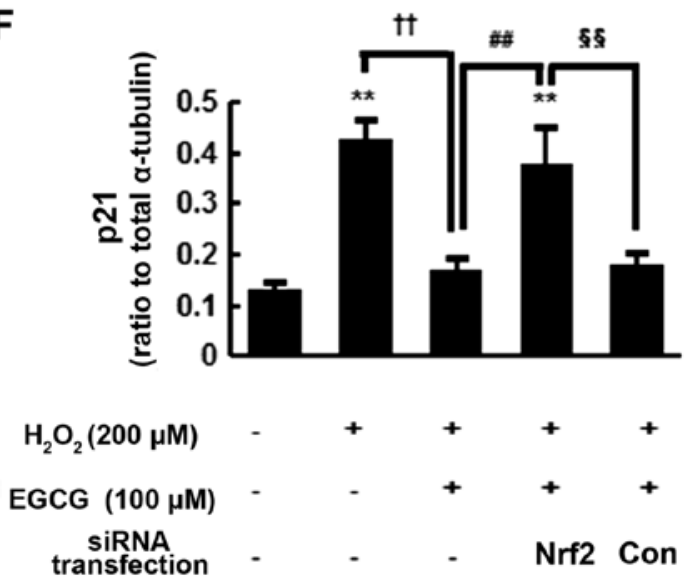

Figure 4. Nuclear factor-erythroid 2-related factor 2 ( Nrf2) activation mediated by epigallocatechin-3-gallate (EGCG) pre-treatment suppresses $\mathrm{H}_{2} \mathrm{O}_{2}$-induced senescence and the expression of acetyl-p53 and p21 in human mesenchymal stem cells (hMSCs). (A) Senescence-associated $\beta$-galactosidase (SA $\beta$-gal) staining analysis of control, $\mathrm{H}_{2} \mathrm{O}_{2}$-exposed, EGCG-pre-treated/ $\mathrm{H}_{2} \mathrm{O}_{2}$-exposed, EGCG-pre-treated/ $\mathrm{H}_{2} \mathrm{O}_{2}$-exposed/Nrf2-siRNA-transfected and EGCG-pre-treated/ $\mathrm{H}_{2} \mathrm{O}_{2}$-treated/control-siRNA-transfected cells. hMSCs were transiently transfected for $48 \mathrm{~h}$ with either Nrf2 or control siRNA and treated with $100 \mu \mathrm{M}$ EGCG for $6 \mathrm{~h}$ followed by $\mathrm{H}_{2} \mathrm{O}_{2}$ exposure $(200 \mu \mathrm{M}, 2 \mathrm{~h})$. Twenty-four hours after $\mathrm{H}_{2} \mathrm{O}_{2}$ exposure, the cells were subjected to SA $\beta$-gal staining (blue cytoplasmic stain). Scale bar, $200 \mu \mathrm{m}$. (B) Quantification of SA $\beta$-gal activity. (C) Western blot analysis and quantification of Nrf2 at 48 h after Nrf2 siRNA or control siRNA transfection. (D-F) Western blot analysis and quantification of acetyl-p53 and p21 protein levels in each group. The levels determined in four independent experiments are presented as the means \pm SEM. ${ }^{*} \mathrm{P}<0.05$ and ${ }^{* *} \mathrm{P}<0.01$ vs. the control; ${ }^{\dagger \dagger} \mathrm{P}<0.01$ vs. the $\mathrm{H}_{2} \mathrm{O}_{2}$ group. ${ }^{\#} \mathrm{P}<0.05$ and ${ }^{\# \#} \mathrm{P}<0.01$ vs. the EGCG group; ${ }^{\S} \mathrm{P}<0.05$ and ${ }^{\S \S} \mathrm{P}<0.01$ vs. the siNrf2 transfection group. ANOVA followed by a post hoc Newman-Keuls test.

pre-treatment suppresses $\mathrm{H}_{2} \mathrm{O}_{2}$-induced cellular senescence and the expression of acetyl-p53 and p21 in hMSCs (Fig. 5).

\section{Discussion}

The therapeutic applications of hMSCs are often limited by various factors, including senescence caused by the inadequate culture conditions that affect their capacity for self-renewal and differentiation (3-5). Therefore, modulating hMSCs to block oxidative stress-induced cellular senescence may improve their clinical utility. Oxidative stress has been shown to induce cellular senescence as previously observed in human primary cells and hMSCs $(6,12,21)$. In the present study, we also observed a significant increase in the number 


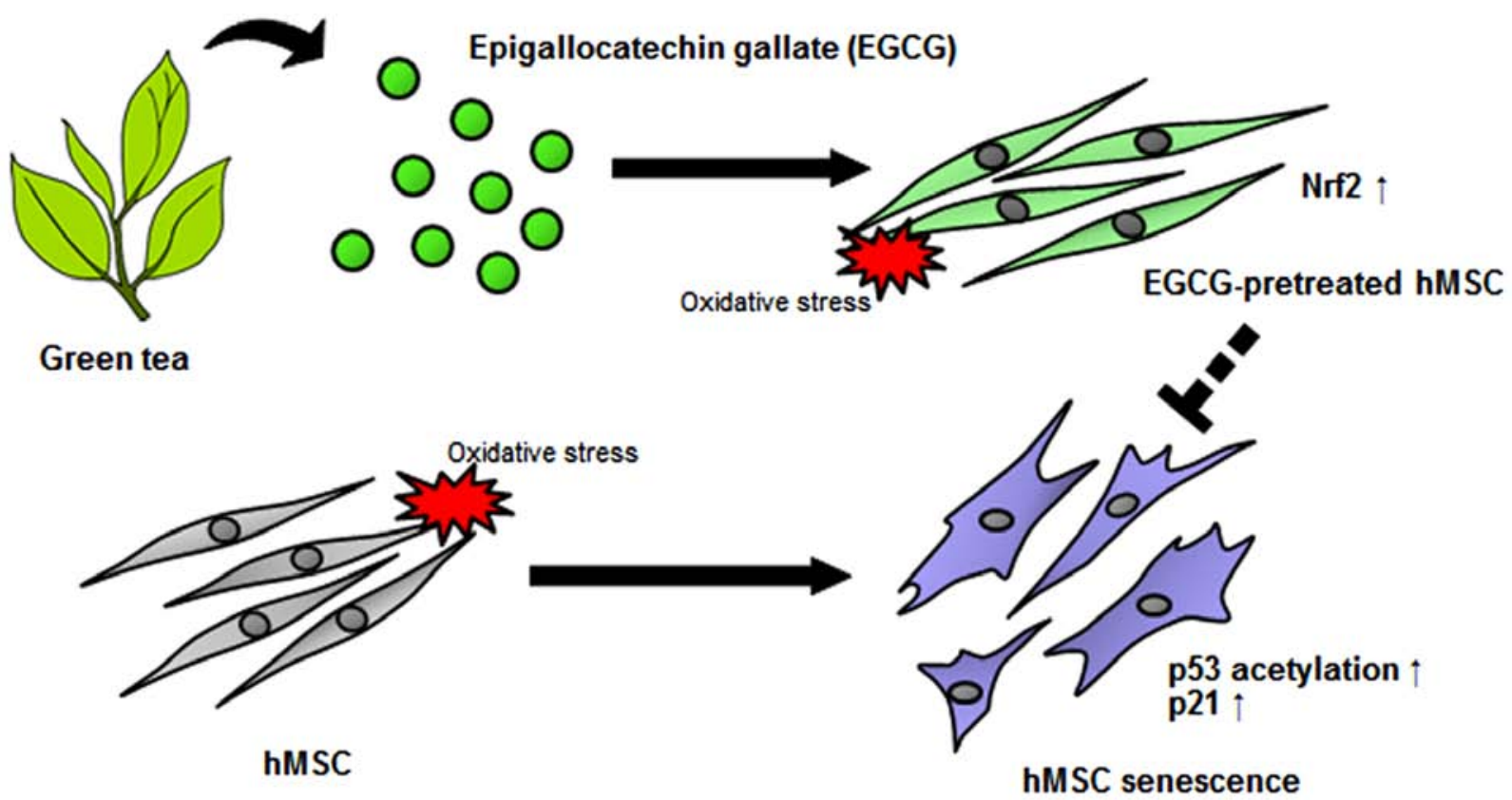

Figure 5. Diagram of novel molecular mechanisms underlying the anti-senescent effect of epigallocatechin-3-gallate (EGCG) in $\mathrm{H}_{2} \mathrm{O}_{2}$-exposed human mesenchymal stem cells (hMSCs). EGCG prevents $\mathrm{H}_{2} \mathrm{O}_{2}$-induced oxidative stress by upregulating nuclear factor-erythroid 2-related factor 2 (Nrf2) and downregulating the p53/p21 signaling pathway. Nrf2 activation by EGCG pre-treatment suppresses $\mathrm{H}_{2} \mathrm{O}_{2}$-induced cellular senescence and the expression of acetyl-p53 and p21 in hMSCs, which suggests a potential role for Nrf2 in p53/p21 regulation to thereby prevent oxidative stress-induced cellular senescence in hMSCs.

of SA $\beta$-gal-positive hMSCs following $\mathrm{H}_{2} \mathrm{O}_{2}$ exposure, which induces cellular senescence by generating intracellular $\operatorname{ROS}(3,4)$.

EGCG, a polyphenol, is a strong neutralizing agent of excessive ROS and induces Nrf2 expression (17). Nrf2 plays an important role in the cellular antioxidant defense system by activating the expression of antioxidant and detoxifying genes, such as superoxide dismutase, heme oxygenase 1, and glutathione S-transferases. These genes have been shown to protect cells against oxidative stress caused by ROS by restoring redox homeostasis and inhibiting oxidative damage (20). A recent study has reported that EGCG suppressed $\mathrm{H}_{2} \mathrm{O}_{2}$-mediated oxidative stress in hMSCs (16). Consistently, our results also demonstrated that EGCG prevented $\mathrm{H}_{2} \mathrm{O}_{2}$-induced senescence in hMSCs.

ARE-mediated antioxidant gene expression is a widely accepted model for the activity of EGCG (20). In general, the serine/threonine residues of Nrf2 are phosphorylated by protein kinases such as PI3K, ERK, p38 and JNK thereby enhancing the nuclear translocation of Nrf2 and subsequent ARE binding. Oxidized or other reactive forms of EGCG conjugate with glutathione (GSH) and decrease cellular GSH concentrations, which leads to a disruption of the redox state and the activation of upstream protein kinases, triggering Nrf2 phosphorylation. It is also plausible that EGCG may oxidize or modify specific cysteine thiol groups in Keap1 that allow the nuclear translocation of Nrf2. We observed the marked translocation of Nrf2 into the nuclei after EGCG treatment (Fig. 3). Both of these are plausible mechanisms for EGCG-induced Nrf2 activation as electrophilic agents or compounds have been reported to interact with cysteine residues directly and stimulate Nrf2 dissociation (22). p53 acetylation has been shown to promote cellular senescence in addition to activating growth suppressive genes $(23,24)$. The first confirmed downstream target of p53, $\mathrm{p} 21$, is an essential regulator of p53-dependent cell cycle arrest which leads to cell cycle arrest in response to DNA damage. As a cyclin-dependent kinase inhibitor, p21 regulates the function of cyclin D1/CDK4 and cyclin E/CDK2 complexes and induces the accumulation of hypophosphorylated $\mathrm{Rb}$, which leads to $\mathrm{Rb}$ binding with E2F transcription factors, resulting in cell cycle arrest $(25,26)$. In addition, previous studies have shown that p21 is a key regulator of cellular senescence in human primary cells $(27,28)$.

Recent studies have challenged the known paradigm of Nrf2. The inhibition of Nrf2 by caveolin-1, a structural protein of caveolae, reduces its cellular antioxidant response following $\mathrm{H}_{2} \mathrm{O}_{2}$ exposure (29). The inhibition of Nrf2 also suppresses the expression of murine double minute (Mdm2), an oncogene which promotes p53 degradation, resulting in p53 pathway activation (30). In addition to the Keap1-Nrf2 complex formation, caveolin-1 and/or Mdm2 may be candidates responsible for modulating p53 acetylation and p21 activation in hMSCs in response to oxidative stress. However, further studies are warranted in order to elucidate the physiological relevance of these mechanisms.

In conclusion, our results are consistent with the hypothesis that Nrf2 activation inhibits oxidative stress in cells. The upregulation of Nrf2 by EGCG prevented oxidative stress-induced cellular senescence through the downregulation of p53 acetylation and p21 in hMSCs. These findings demonstrate that EGCG is capable of increasing Nrf2 activation in hMSCs and suggest a novel approach for preventing the oxidative stress-induced cellular senescence of human stem cells. 


\section{Acknowledgements}

The present study was supported by the Basic Science Research Program through the National Research Foundation of Korea (M-SC, NRF-2015R1D1A1A01056950) funded by the Ministry of Education, and by a grant from the Korean Health Technology R\&D Project (M-SC, A120476), Ministry of Health and Welfare, Republic of Korea.

\section{References}

1. Pittenger MF1, Mackay AM, Beck SC, Jaiswal RK, Douglas R, Mosca JD, Moorman MA, Simonetti DW, Craig S and Marshak DR: Multilineage potential of adult human mesenchymal stem cells. Science 284: 143-147, 1999.

2. Sherman LS, Munoz J, Patel SA, Dave MA, Paige I and Rameshwar P: Moving from the laboratory bench to patients bedside: considerations for effective therapy with stem cells. Clin Transl Sci 4: 380-386, 2011.

3. Kuilman T, Michaloglou C, Mooi WJ and Peeper DS: The essence of senescence. Genes Dev 24: 2463-2479, 2010.

4. López-Otín C, Blasco MA, Partridge L, Serrano M and Kroemer G: The hallmarks of aging. Cell 153: 1194-1217, 2013.

5. Oh J, Lee YD and Wagers AJ: Stem cell aging: mechanisms, regulators and therapeutic opportunities. Nat Med 20: 870-880, 2014.

6. Brandl A, Meyer M, Bechmann V, Nerlich M and Angele P: Oxidative stress induces senescence in human mesenchymal stem cells. Exp Cell Res 317: 1541-1547, 2011.

7. Campisi J and d'Adda di Fagagna F: Cellular senescence: when bad things happen to good cells. Nat Rev Mol Cell Biol 8: 729-740, 2007.

8. Kume S, Haneda M, Kanasaki K, Sugimoto T, Araki S, Isono M, Isshiki K, Uzu T, Kashiwagi A and Koya D: Silent information regulator 2 (SIRT1) attenuates oxidative stress-induced mesangial cell apoptosis via p53 deacetylation. Free Radic Biol Med 40: 2175-2182, 2006.

9. Langley E, Pearson M, Faretta M, Bauer UM, Frye RA, Minucci S, Pelicci PG and Kouzarides T: Human SIR2 deacetylates p53 and antagonizes PML/p53-induced cellular senescence. EMBO J 21: 2383-2396, 2002.

10. Luo J, Nikolaev AY, Imai S, Chen D, Su F, Shiloh A, Guarente L and $\mathrm{Gu}$ W: Negative control of $\mathrm{p} 53$ by $\operatorname{Sir} 2 \alpha$ promotes cell survival under stress. Cell 107: 137-148, 2001.

11. Vaziri H, Dessain SK, Ng Eaton E, Imai SI, Frye RA, Pandita TK, Guarente L and Weinberg RA: hSIR2(SIRT1) functions as an NAD-dependent p53 deacetylase. Cell 107: 149-159, 2001.

12. Han DW, Lee MH, Kim B, Lee JJ, Hyon SH and Park JC: Preventive effects of epigallocatechin-3-O-gallate against replicative senescence associated with p53 acetylation in human dermal fibroblasts. Oxid Med Cell Longev 2012: 850684, 2012.

13. Anderson RF, Fisher LJ, Hara Y, Harris T, Mak WB, Melton LD and Packer JE: Green tea catechins partially protect DNA from (.)OH radical-induced strand breaks and base damage through fast chemical repair of DNA radicals. Carcinogenesis 22: 1189-1193, 2001.

14. Chow HH, Cai Y, Alberts DS, Hakim I, Dorr R, Shahi F, Crowell JA, Yang CS and Hara Y: Phase I pharmacokinetic study of tea polyphenols following single-dose administration of epigallocatechin gallate and polyphenon E. Cancer Epidemiol Biomarkers Prev 10: 53-58, 2001.
15. Higdon JV and Frei B: Tea catechins and polyphenols: health effects, metabolism, and antioxidant functions. Crit Rev Food Sci Nutr 43: 89-143, 2003.

16. Yagi H, Tan J and Tuan RS: Polyphenols suppress hydrogen peroxide-induced oxidative stress in human bone-marrow derived mesenchymal stem cells. J Cell Biochem 114: 1163-1173, 2013.

17. Surh YJ, Kundu JK, Na HK and Lee JS: Redox-sensitive transcription factors as prime targets for chemoprevention with anti-inflammatory and antioxidative phytochemicals. J Nutr 135 (Suppl 12): 2993S-3001S, 2005.

18. Hayes JD and McMahon M: NRF2 and KEAP1 mutations: permanent activation of an adaptive response in cancer. Trends Biochem Sci 34: 176-188, 2009.

19. Itoh K, Wakabayashi N, Katoh Y, Ishii T, Igarashi K, Engel JD and Yamamoto M: Keap1 represses nuclear activation of antioxidant responsive elements by Nrf2 through binding to the amino-terminal Neh2 domain. Genes Dev 13: 76-86, 1999.

20. Nguyen T, Nioi P and Pickett CB: The Nrf2-antioxidant response element signaling pathway and its activation by oxidative stress. J Biol Chem 284: 13291-13295, 2009.

21. Burova E, Borodkina A, Shatrova A and Nikolsky N: Sublethal oxidative stress induces the premature senescence of human mesenchymal stem cells derived from endometrium. Oxid Med Cell Longev 2013: 474931, 2013.

22. Dinkova-Kostova AT, Holtzclaw WD and Wakabayashi N: Keap1, the sensor for electrophiles and oxidants that regulates the phase 2 response, is a zinc metalloprotein. Biochemistry 44: 6889-6899, 2005.

23. Bond J, Haughton M, Blaydes J, Gire V, Wynford-Thomas D and Wyllie F: Evidence that transcriptional activation by $\mathrm{p} 53$ plays a direct role in the induction of cellular senescence. Oncogene 13: 2097-2104, 1996.

24. Luo J, Li M, Tang Y, Laszkowska M, Roeder RG and Gu W: Acetylation of p53 augments its site-specific DNA binding both in vitro and in vivo. Proc Natl Acad Sci USA 101: 2259-2264, 2004.

25. el-Deiry WS, Tokino T, Velculescu VE, Levy DB, Parsons R, Trent JM, Lin D, Mercer WE, Kinzler KW and Vogelstein B: WAF1, a potential mediator of p53 tumor suppression. Cell 75: 817-825, 1993.

26. Harper JW, Adami GR, Wei N, Keyomarsi K and Elledge SJ: The p21 Cdk-interacting protein Cip1 is a potent inhibitor of G1 cyclin-dependent kinases. Cell 75: 805-816, 1993.

27. Brown JP, Wei W and Sedivy JM: Bypass of senescence after disruption of p21CIP1/WAF1 gene in normal diploid human fibroblasts. Science 277: 831-834, 1997.

28. Herbig U, Wei W, Dutriaux A, Jobling WA and Sedivy JM: Real-time imaging of transcriptional activation in live cells reveals rapid up-regulation of the cyclin-dependent kinase inhibitor gene CDKN1A in replicative cellular senescence. Aging Cell 2: 295-304, 2003.

29. Volonte D, Liu Z, Musille PM, Stoppani E, Wakabayashi N, Di YP, Lisanti MP, Kensler TW and Galbiati F: Inhibition of nuclear factor-erythroid 2-related factor (Nrf2) by caveolin-1 promotes stress-induced premature senescence. Mol Biol Cell 24: 1852-1862, 2013.

30. You A, Nam CW, Wakabayashi N, Yamamoto M, Kensler TW and Kwak MK: Transcription factor Nrf2 maintains the basal expression of Mdm2: an implication of the regulation of p53 signaling by Nrf2. Arch Biochem Biophys 507: 356-364, 2011. 